\title{
Nursing staff's and physicians' acquisition of competences and attitudes to interprofessional education and interprofessional collaboration in pediatrics
}

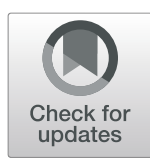

\author{
Christine Straub', Andrea Heinzmann ${ }^{1}$, Marcus Krueger ${ }^{2}$ and Sebastian F. N. Bode ${ }^{1 *}$ (D)
}

\begin{abstract}
Background: Interprofessional education (IPE) is deemed essential for interprofessional collaboration (IPC) in healthcare systems. IPC has positive effects for both patients and healthcare professionals. Especially in pediatrics, IPC is paramount for adequate care of patients and their families though there is a lack of data on the attitudes towards IPE and IPC and acquisition of respective competences in pediatric nursing and medical staff.

Methods: Frequencies of interactions and attitudes towards IPE and IPC, with a focus on acquisition of competences for IPE and IPC, of nurses $(N=79)$ and physicians $(N=70)$ in a large pediatric university hospital were evaluated with an online questionnaire.

Results: All participants worked as part of interprofessional teams, mostly consisting of nurses and physicians. The majority (94.9\% ( $n=75)$ of nurses and 100\% ( $n=70)$ of physicians) highly valued IPC. Medical doctors acquired most competences important for IPC during day-to-day work and reported a substantial lack of IPE. Nursing staff on the other hand did report significant interprofessional education during their training as well as ongoing interprofessional learning during day-to-day work. Nurses also appreciated IPE more.

Conclusions: Even though IPC is commonly reported in nurses and physicians working at a large pediatric university hospital there is a lack of structured IPE. A focus should be on IPE for nurses and physicians to enable them to effectively collaborate together. Political and local initiatives for IPE are gaining momentum but still need to be established nationally and internationally.
\end{abstract}

Keywords: Interprofessional collaboration, Interprofessional education, Interprofessional Questionnaire, Competence acquisition, Pediatrics

\section{Background}

Interprofessional collaboration (IPC) “... takes place when health professionals with different professional backgrounds work with patients, families, and caregivers

\footnotetext{
*Correspondence: Sebastian.Bode@uniklinik-freiburg.de

${ }^{1}$ Center for Pediatrics - Department of general pediatrics, adolescent medicine, and neonatology, Medical Center, Medical Faculty, University of Freiburg, Mathildenstrasse 1, 79106 Freiburg, Germany

Full list of author information is available at the end of the article
}

to ensure the highest quality of care..." [1]. IPC is a mainstay of today's healthcare [2]. It has been shown that efficient IPC can improve patient outcomes, reduce healthcare costs, and improve healthcare providers' work satisfaction [3-6]. Especially in pediatrics the interaction of healthcare professionals with patients and their families as well as the collaboration of different healthcare professionals, are crucial for patient care [7-10].

C C The Author(s). 2020 Open Access This article is licensed under a Creative Commons Attribution 4.0 International License, which permits use, sharing, adaptation, distribution and reproduction in any medium or format, as long as you give appropriate credit to the original author(s) and the source, provide a link to the Creative Commons licence, and indicate if changes were made. The images or other third party material in this article are included in the article's Creative Commons licence, unless indicated otherwise in a credit line to the material. If material is not included in the article's Creative Commons licence and your intended use is not permitted by statutory regulation or exceeds the permitted use, you will need to obtain permission directly from the copyright holder. To view a copy of this licence, visit http://creativecommons.org/licenses/by/4.0/ The Creative Commons Public Domain Dedication waiver (http://creativecommons.org/publicdomain/zero/1.0/) applies to the data made available in this article, unless otherwise stated in a credit line to the data. 
Interprofessional education (IPE) has been defined as students from two or more professions learning together, about, and from each other [1]. IPE can lay a foundation for later effective IPC, especially regarding the procurement of essential skills and competences needed for interprofessional work [1, 11-16].

For effective IPC individuals need to acquire a multitude of different competences. Different frameworks have identified competences including values and ethics in IPC, team-based practice, communication skills, and others as essential for IPC [17-20]. The CanMeds physician competency framework for the first time strengthened the role of physicians as members of an interprofessional healthcare team [18]. Since then this concept has been adopted to different national frameworks for different health care professions [17-23]. Healthcare education still takes place monoprofessionally though in many countries, including Germany [24], but IPE is being integrated in more and more undergraduate and postgraduate curricula worldwide [25-27]. Therefore future health care professionals might be better prepared for their later work in interprofessional teams.

A lack of IPE and IPC has been demonstrated for both physicians and other health care professionals before [28-30]. In a previous study that focused on health care professionals other than nurses our group could show that physicians mostly received training regarding IPC while working [10]. As in a hospital setting the most common interprofessional interaction is that between medical and nursing staff [31], we decided to expand the study and to invite nurses of the same pediatric university hospital to participate.

The study was designed to evaluate pediatric nurses' and physicians' frequency of interactions with other health care professionals, attitudes towards IPE and IPC and to investigate the self-reported acquisition of competences required for IPE and IPC.

\section{Methods}

\section{Questionnaire construction}

We reviewed existing questionnaires which have been developed for measuring attitudes towards IPC including the Readiness for Interprofessional Learning Scale (RIPLS) [21], the Generic Role Perception Questionnaire (GRPQ) [22], the Interdisciplinary Education Perception Scale (IEPS) [23], and the Index of Interdisciplinary Collaboration (IIC) [24, 25]. Not all of the questionnaires were validated in German and none covered essential aspects that we deemed important: Most instruments lacked detailed questions regarding specific competences for IPE/IPC. Competences laid out in different IPE/IPC frameworks were reviewed $[17,18,22]$ and added to our own questionnaire. Previous questionnaires did not differentiate if certain competences were acquired during education or while working. Additionally we put an emphasis on a short questionnaire. Therefore, we developed a new questionnaire focusing on the acquisition of competences, for both undergraduate studies and work. Nineteen items were selected in order to construct the questionnaire. Answers were graded from " 1 = very frequently to $5=$ never" for three questions regarding frequency of IP interactions and "1 = totally agree/very important/very helpful to 5 = strongly disagree/very insignificant/very hindering" for ten questions. Two questions regarding opportunities for IP learning were graded from " $1=$ too many to $6=$ none". Two open ended questions were included: "What are your wishes for the future of interprofessional collaboration?" and "What are your wishes for the future of interprofessional education?" The remainder of the questions comprised boxes to tick. Six items on demographics of the study participants were also included. Detailed data on the questionnaire construction and the questionnaire itself have been published before [10]. The questionnaire, including a list of competences assessed in this study, is available here: https://www.egms.de/tools/download. jsp?path=journals/zma/2016-33/zma001016.a1en. pdf\&mime=application/pdf\&name=Attachment_13. 08.15.pdf.

\section{Study design}

A cross-sectional study using convenience sampling was conducted. The questionnaire was provided electronically (Questback GmbH. Published 2015. EFS survey, version 10.5., Cologne, Germany) to be filled in online. All nurses and physicians at a large pediatric university hospital in Germany (Center for Pediatrics Freiburg - ZKJ) were invited to participate. Participants were able to fill in the questionnaire over a period of four weeks (physicians July 1st, 2014 to July 31st, 2014; nurses November 4th, 2015 to December 5th, 2015). A reminder email was sent after two weeks of initiation of the study.

\section{Study participants}

A total of 79 nurses (response rate $37.3 \%$ ) and 70 physicians (response rate 58.4\%) participated in the study. The physicians were part of a larger cohort reported before [10]. Table 1 shows the demographics of the study participants.

\section{Data protection and ethical considerations}

The study was conducted according to national data protection regulations. All data were collected anonymously. The employees' committee of the University of Freiburg, Germany, approved the study. In addition, the ethics committee of the University of Freiburg, 
Table 1 Demographics of the study participants. N/A = not applicable, no = number

\begin{tabular}{lll}
\hline Participants & $\begin{array}{l}\text { Nurses } \\
\text { no }(\%)\end{array}$ & $\begin{array}{l}\text { Physicians } \\
\text { no (\%) }\end{array}$ \\
\hline $\begin{array}{l}\text { Invited to participate } \\
\text { Completed the questionnaire }\end{array}$ & 212 & 120 \\
Gender & $79(37.3)$ & $70(58.4)$ \\
$\quad$ Female & $72(91.1)$ & $39(55.7)$ \\
$\quad$ Male & $7(8.9)$ & $31(44.3)$ \\
Work experience & & \\
$\quad \leq 4$ years & $30(37.9)$ & $19(27.1)$ \\
4-10 years & $25(31.6 \%)$ & $26(37.1)$ \\
$\geq 10$ years & $37(46.8)$ & $25(35.7)$ \\
\hline
\end{tabular}

Germany, waived the need for ethical approval for this study.

\section{Data analysis}

Descriptive statistics (e.g., mean and standard deviation) were used to describe the demographics of the study participants and survey data. Inferential statistics (e.g., unpaired t-tests, Kruskal-Wallis-tests) were used to determine differences and Bonferroni correction for multiple testing was applied as appropriate. Survey data were analyzed using SPSS version 23.0. Qualitative evaluation of the open-ended responses was performed according to the content analysis after Mayring [32]. One open-ended question focused on the future of IPC, one question was used to assess future needs for IPE. Participants' answers to the open ended questions were analyzed using a deductive approach. Categories identified were structure/time, social skills/competences, interaction of different health care professionals, and conflict management/error culture for both IPC and IPE. The Figure was generated using GraphPad Prism version 7.01, GraphPad Software, La Jolla California USA, www.graphpad.com.

\section{Results \\ Interprofessional collaboration}

Overall, 94.9\% $(N=75)$ of nurses and 100\% $(N=70)$ of physicians either "highly valued" or "very highly valued" IPC. Physicians reported to work more frequently with psychologists, social workers and therapeutical educationists (Table 2). There were no significant differences between nurses and physicians in working together with physiotherapists or school teachers.

Concerning patient care, physicians reported more frequently to reach joint decisions with other physicians, psychologists, social workers, and therapeutical educationists than did nurses (Table 2). There were no significant differences between nurses and physicians in in the frequency of involvement in the decision making process with other nurses, physiotherapists and nursery school teachers. Both professional groups most frequently interacted with nurses and physicians.

The collaboration with other physicians for treatment success was deemed more important by physicians (Mean $(M)=1.01$, standard deviation $(S D) \pm .12$ ) than by nurses $\left(M=1.24, S D \pm .65, t_{(147)}=2.89, p=.032\right)$. There were no differences in the appreciation for other health care professions regarding treatment success.

Physicians $(M=1.09, S D \pm .28)$ rated IPC more important than nurses $(M=1.24, S D \pm .54), t_{(145)}=2.16$, $p=.032)$. There were no significant differences regarding additional qualifications, having a board of pediatrics certification, and participant-rated importance of IPC regarding the reported importance of IPC.

Table 2 Significant differences in frequencies of interactions of nurses and physicians with other health care professionals. Answers graded vom " 1 = very frequently to $5=$ never". *Therapeutical educationists support children with special needs and their families

\begin{tabular}{|c|c|c|c|c|c|}
\hline Item: How often do you work together with... & & Psychologists & $\begin{array}{l}\text { Nursery school } \\
\text { teachers }\end{array}$ & Social workers & $\begin{array}{l}\text { Therapeutical } \\
\text { educationists* }\end{array}$ \\
\hline \multirow[t]{2}{*}{ Nurses } & & $\begin{array}{l}M=2.58 \\
S D \pm .856\end{array}$ & $\begin{array}{l}M=3.73, \mathrm{SD} \pm \\
1.13\end{array}$ & $\begin{array}{l}M=2.94 \\
S D \pm .88\end{array}$ & $M=3.96, S D \pm 1.09$ \\
\hline & & $\begin{array}{l}t_{(147)}=5.21 \\
p<.001\end{array}$ & $\begin{array}{l}t_{(147)}=2,16 \\
p=.032\end{array}$ & $\begin{array}{l}\mathrm{t}_{(147)}=3.82 \\
p<.001\end{array}$ & $t_{(147)}=3.71, p<.001$ \\
\hline Physicians & & $\begin{array}{l}M=1.93 \\
S D \pm .64\end{array}$ & $3.37, S D \pm .89$ & $\begin{array}{l}M=2.4 \\
S D \pm .82\end{array}$ & $M=3.30, S D \pm 1.08$ \\
\hline $\begin{array}{l}\text { Item: How often do you make decisions in the IP } \\
\text { team together with... }\end{array}$ & Physicians & Psychologists & Teachers & Social workers & $\begin{array}{l}\text { Therapeutical } \\
\text { educationists }\end{array}$ \\
\hline \multirow[t]{2}{*}{ Nurses } & $\begin{array}{l}M=1.51 \\
S D \pm .69\end{array}$ & $\begin{array}{l}M=3.19 \\
S D \pm 1.05\end{array}$ & $M=4.25, S D \pm .93$ & $\begin{array}{l}M=3.89 \\
S D \pm .96\end{array}$ & $M=4.23, S D \pm .99$ \\
\hline & $\begin{array}{l}t_{(147)}=4.92 \\
p<.001\end{array}$ & $\begin{array}{l}t_{(147)}=6.65 \\
p<.001\end{array}$ & $\begin{array}{l}t_{(147)}=2.49 \\
p=.014\end{array}$ & $\begin{array}{l}t_{(147)}=5.84 \\
p<.001\end{array}$ & $t_{(147)}=3.24, p=.001$ \\
\hline Physicians & $\begin{array}{l}M=1.07 \\
S D \pm .26\end{array}$ & $\begin{array}{l}M=2.16 \\
S D \pm .81\end{array}$ & $M=3.89, S D \pm .86$ & $\begin{array}{l}M=2.83 \\
S D \pm .93\end{array}$ & $M=3.69, S D \pm 1.06$ \\
\hline
\end{tabular}


IPE and acquisition of competences

Nurses reported significantly more opportunities for IPE during undergraduate training $[(M=3.89 ; S D \pm 1.22)$ rather than during work $(M=4.28 ; S D \pm 1.12) ; t_{(78)}=2.16$, $p<.001]$. However, physicians experienced less IPE during medical school $(M=4.73 ; S D \pm 1.03)$ than during work $\left(M=3.94 ; S D \pm 1.19, t_{(69)}=4.17, p<.001\right)$. Concerning IPE, physicians had significantly fewer opportunities to learn together with other health care professionals than nurses during undergraduate studies $\left(\mathrm{t}_{(147)}=4.52, p<.001\right)$. Physicians reported to have acquired more interprofessional competences through work experience rather than through undergraduate studies. In contrast, nurses acquired interprofessional competences while they were studying (Fig. 1). Both professional groups reported equal opportunities for IPC and interprofessional competence acquisition while working $\left(\mathrm{t}_{(147)}=1.77, p=.078\right)$. Nurses $(M=1.81 ; S D \pm$ $.68)$ in general valued IPE higher than physicians $(M=$ 2.27; $\left.S D \pm .98, t_{(149)}=3.37, p<.001\right)$.

\section{Routine interprofessional collaboration}

Nurses reported both handlings of role conflicts and the appreciation of other professional groups more critically than did physicians. Nursing staff also stated that all relevant professional groups should be involved in the decision making process. Physicians thought more frequently that a doctor should lead the interprofessional team (Table 3). Work experience did not have an influence on perceived IPC.

\section{Requirements for IPC}

Nurses rated IPE $(M=1.77, S D \pm .68)$ and communication skills $(M=1.04, S D \pm .19)$ as more essential for IPC than did physicians $\left(M=2.23, S D \pm .78, t_{(142)}=3.37\right.$, $p<.001$ and $M=1.19, t_{(143)}=2.97, S D \pm .39, p=.003$, respectively).

Work experience had no influence on the perceived importance of different requirements for IPC.

\section{Qualitative evaluation}

Through content analysis based on Mayring [32], we identified areas that participants deemed most important for future efficient interprofessional collaboration and interprofessional education.

\section{Qualitative evaluation - Interprofessional collaboration}

Structure and time: Establishing structures that support interprofessional collaboration on the hospital wards were mentioned frequently. These circumstances include both time and structural changes during day-to-daywork, mentioned as "to call for interprofessional collaboration" and "to intensify IPC", for example.

Social skills, interaction and competences: Participants aspired for certain social skills and attitudes, which are needed in everyday interaction. This includes tolerance, "to reduce prejudices", and patience, "to be able to make

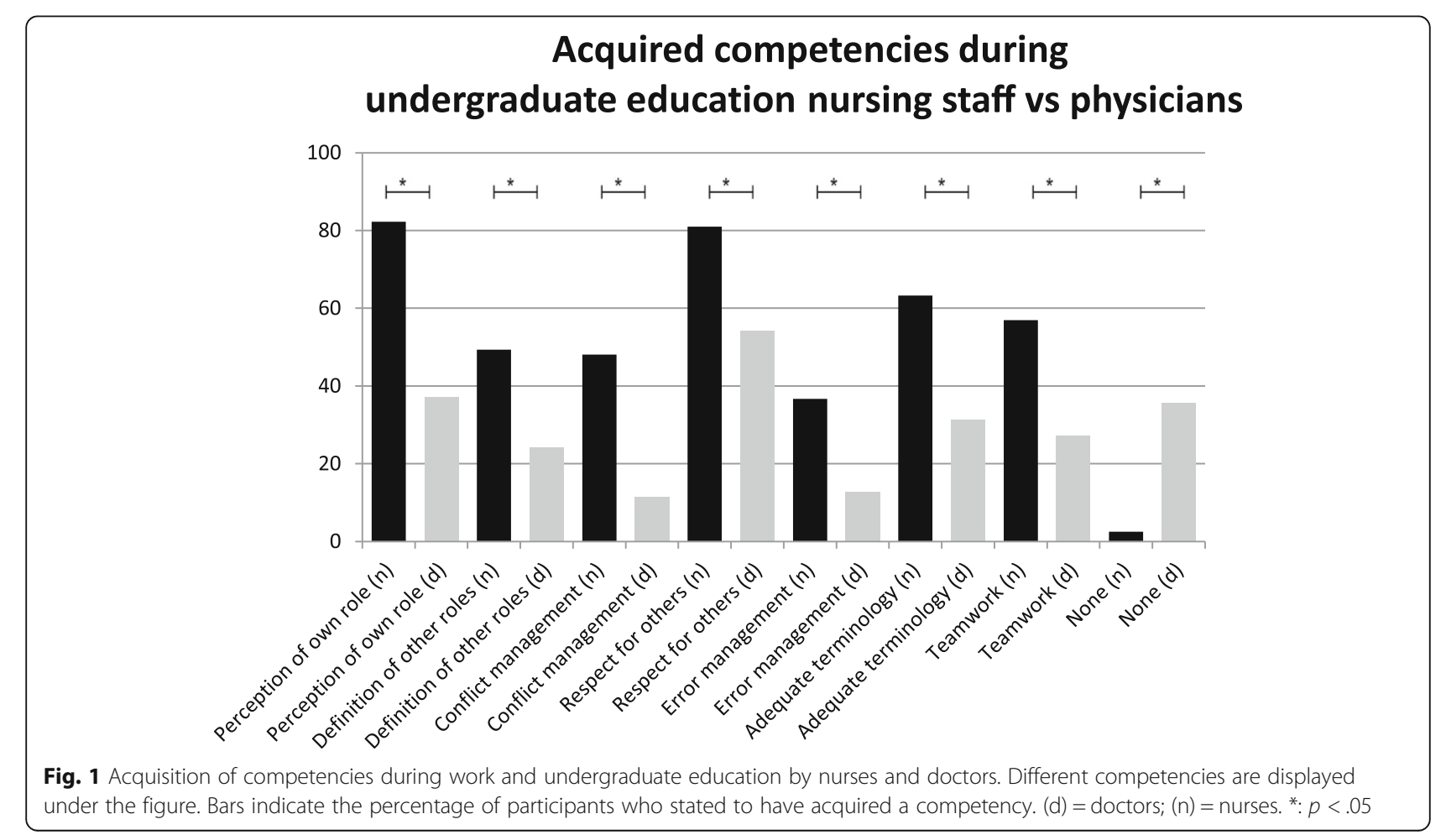


Table 3 Significant differences in attitudes toward IPC depending on profession. Answers graded " $1=$ totally agree to $5=$ strongly disagree"

\begin{tabular}{llll}
\hline & Nurses & Physicians & \\
& Mean (SD) & Mean (SD) & t/p-value \\
\hline All relevant professional groups should be involved in the decision-making process. & $1.33( \pm .59)$ & $1.71( \pm .8)$ & $t_{(143)}=3.36, p=.001$ \\
Role conflicts in interprofessional teams are handled adequately in everyday work. & $3.51( \pm 1.06)$ & $3.06( \pm .87)$ & $t_{(143)}=2,81, p=.006$ \\
The work of other professional groups is not appreciated enough during every day work. & $1.87( \pm 1.04)$ & $2.27( \pm 1.02)$ & $t_{(143)}=2.35, p=.02$ \\
An interprofessional team should be led by a medical doctor. & $3.63( \pm 1.06)$ & $2.34( \pm 1.02)$ & $t_{(143)}=7.53, p<.001$ \\
\hline
\end{tabular}

decisions at the same pace". Furthermore many participants emphasized the importance "to respect..." "other professional groups", "for different educational levels and experiences" as well "in our dealing with each other and caring for the opinions of others".

Conflict management and error culture: Participants stated to "not settle conflicts at a personal level" but "to address problems and misunderstandings". A communication and error culture needs to be established as "information about patients is often not disclosed" and "criticism is taken personally very quickly".

\section{Qualitative evaluation - Interprofessional education}

According to the participants' statements, we identified main categories concerning the wishes for the future of the interprofessional education.

Structure and Time: Participants called for "more structure for interprofessional education with other disciplines" and "more and better integration" of IPE in the curriculum. Providing more time resources for IPE during undergraduate studies of physicians and training of nurses were essential for the participants.

Social skills, interaction and competences: Participants put a special focus on interaction including flat hierarchies. For the future of IPE the participants hoped for an efficient interprofessional collaboration both on the ward and during education. This included "more and early contact of different disciplines", as well as "interprofessional cooperation and communication during training".

\section{Discussion}

This study was designed to assess pediatric nurses' and physicians' frequency of interactions with other health care professionals, attitudes towards IPE and IPC and to investigate the self-reported acquisition of competences required for IPE and IPC.

The majority of physicians and nurses, who participated in the study, valued the importance of IPC. All reported to work interprofessionally routinely - not surprising as IPC is an integral part of daily practice in healthcare systems $[2,8]$. The most frequent interprofessional interaction reported was between nurses and physicians as has been reported before [31] - hinting that those health professions might be the most important ones when limited resources for IPE and IPC have to be distributed.

In our cohort physicians stated to work significantly more with other health care professionals and to include other health care professionals more frequently in the decision making process regarding patients than did nurses. The cultural setting of the study has to be taken into account here: In Germany, as in some other countries [33], physicians are responsible for the overall care of the patients and therefore have to gather information from all involved health care professionals. In other healthcare systems nursing staff has a much more central role in patient care than in Germany [34, 35]. Additionally different education systems, especially in nursing, exist [35]. Therefore our results cannot be generalized.

In our study nurses rated the value of IPE higher than physicians but no differences were observed regarding the value of IPC. Previous work show an unclear picture: Some studies showed that nursing students were more ready for IPE than medical students [36, 37]. Another study reported nurses perceived IPE and IPC less important than physicians [38]. Interestingly these differences vanished when learning together. IPE leads to appreciation of interprofessional learning by those involved [16, 39]. Additionally there is even evidence that different professional groups, students, and working professionals all value IPE and IPC [15]. This inconsistency in the literature may be due to the different populations and cultural settings but generally hints at an enthusiasm for IPE and IPC that is further supported by our data. Especially the qualitative data reported here show that participants explicitly wish for IPE and IPC.

The most important findings of our study are the differences in the perception of acquisition of competences among physicians and nurses. While physicians reported a significant lack of competence acquisition during undergraduate studies, nurses reported to have gained those competences during education. This hints at more pronounced implicit practice-based competence acquisition and a lack of explicit IPE for the acquisition of competences in medical students which is also supported by a review elsewhere [40]. Another explanation for this might be that there still is a lack of structured IPE for 
medical students and a more practice based education for nurses in Germany: Nurses experience a 3-year nonuniversity training that involves early contact with patients and other healthcare professions. Training in medical schools in Germany lasts at least 6 years and students only become members of an interprofessional team in their final year, thus giving medical students few opportunities for IPE in the early stages of their studies.

The German NKLM, the Master Plan for Medical Education 2020, and the new draft for medical licensure regulation, as well as similar concepts e.g. in Canada, Switzerland, or the United Kingdom aim at integrating IPE earlier in undergraduate medical education [17-19, $21,22,41]$. Similar concepts are being implemented in education regulations for other health care professionals [23].

Even though there have been considerable efforts to either implement reformed medical curricula and/or to designate more time and energy towards educating medical students in communication in Germany [42], our data suggest that physicians retrospectively assess their acquisition of skills and competences essential for IPC worse than do nurses with a different kind of education. Successful local projects (IP degree for health care professionals, IP child protection seminars, IPE wards (for examples see: [12, 43-48]) have targeted IPE at different German medical schools and might serve as positive examples for others both nationally and internationally something that the participants of our study clearly wish for.

Of positive note physicians seem to catch up in the acquisition of competences for IPC. The self-perceived competence level of practicing nurses and physicians does not differ. This might be a reflection of an ongoing learning process to work competently as part of an interprofessional team. It does put additional workload on junior physicians though, who already have to continue to gain knowledge in their selective fields and have to cope with their new role $[9,21,29]$. Earlier acquisition of interprofessional competences might enable a more efficient start for junior physicians on the wards and can probably improve patient care as well [49]. It may be too early to note positive changes of the re-structuring of medical education or first local projects in Germany. At least in our cohort we were not able to determine differences between physicians who just had finished medical school and those who had been working for over 10 years - but we are just at the beginning of reforming health care education.

\section{Strengths and limitations}

Limitations of the study include the relatively small sample size and the setting as a cross-sectional study with convenience sampling at a single institution. Also recruitment periods were different for physicians and nurses. As no intervention took place we think the possible impact on the results is considerably small. Caution regarding the results has to be taken as the study is built on a self-reported retrospective assessment of interactions and own competences. Reliability and validity of the instrument have not been tested.

Despite the limitations we think the work presented here holds some interesting aspects: This study is the first that evaluates attitudes of nurses and physicians to IPE and IPC in a German pediatric university hospital. The data underline that IPC is already part of day to day work in pediatrics but hint that more IPE could support an easier start for junior doctors in this communicative field of medicine. It would be worthwhile to follow-up medical students and nursing trainees prospectively to gain a more profound understanding of their acquisition of competences. Ideally competences should be measured after proposed standards [50-52] which might be part of a prospective follow-up study.

\section{Conclusions}

Both pediatric nurses and physicians value the importance of IPC in routine clinical practice in pediatrics. Physicians acquire more interprofessional competences through work experience rather than through undergraduate studies. In contrast, nurses acquire interprofessional competences while they are studying. Taken together these results suggest that more focus should be put on IPE in German medical schools to help junior physicians with the acquisition of competences important for IPC before they start working as members of interprofessional teams. Fortunately IPE seems to gain momentum both politically but also locally in Germany. However, further work needs to be performed to establish a prospective assessment of interprofessional competences of nursing and medical students who then progress to working professionals.

\section{Abbreviations \\ GRPQ: Generic Role Perception Questionnaire; IEPS: Interdisciplinary Education Perception Scale; IIC: Index of Interdisciplinary Collaboration; IP: Interprofessional; IPC: Interprofessional Collaboration; IPE : Interprofessional Education; M: Mean; N / n: Number of participants / answers; RIPLS: Readiness for Interprofessional Learning Scale; SD: Standard deviation; ZKJ: Center for Pediatrics Freiburg, Germany}

\section{Acknowledgements}

We would like to express our gratitude to all nurses and physicians who participated in this study.

\section{Authors' contributions}

CS and SFNB designed the study and the questionnaire. AH and MK reviewed the questionnaire. SFNB analyzed the data and wrote up the first draft of the manuscript. CS and SFNB performed the qualitative evaluation. All authors critically revised the manuscript. All authors have read and approved the manuscript.

Funding

No funding was received for the work presented here. 


\section{Availability of data and materials}

The datasets used and/or analyzed during the current study are available from the corresponding author on request.

\section{Ethics approval and consent to participate}

The ethics committee of the University of Freiburg, Germany, waived the need for ethical approval for this study. All participants consented to participate in the study by filling in the questionnaire.

\section{Consent for publication}

Not applicable.

\section{Competing interests}

No restrictions on publication exist related to the funding. The authors report no other conflicts of interest.

\section{Author details}

${ }^{1}$ Center for Pediatrics - Department of general pediatrics, adolescent medicine, and neonatology, Medical Center, Medical Faculty, University of Freiburg, Mathildenstrasse 1, 79106 Freiburg, Germany. ${ }^{2}$ Department of Neonatology, Harlaching, Munich Municipal Hospitals, Munich, Germany.

Received: 20 March 2020 Accepted: 25 June 2020

Published online: 02 July 2020

\section{References}

1. WHO. Framework for action on interprofessional education and collaborative practice2010 2015/07/10:[56 p.].

2. Reeves S, Perrier L, Goldman J, Freeth D, Zwarenstein M. Interprofessional education: effects on professional practice and healthcare outcomes (update). Cochrane Database Syst Rev. 2015;3:CD002213.

3. Zwarenstein M, Goldman J, Reeves S. Interprofessional collaboration: effects of practice-based interventions on professional practice and healthcare outcomes. Cochrane Database Syst Rev. 2009;3:CD000072.

4. D'Amour D, Oandasan I. Interprofessionality as the field of interprofessional practice and interprofessional education: an emerging concept. J Interprof Care. 2005;19(Suppl 1):8-20.

5. Shamian J, El-Jardali F. Healthy workplaces for health workers in Canada: knowledge transfer and uptake in policy and practice. Healthc Pap. 2007;7 Spec No:6-25.

6. Holland R, Battersby J, Harvey I, Lenaghan E, Smith J, Hay L. Systematic review of multidisciplinary interventions in heart failure. Heart. 2005;91 (7): 899-906.

7. Hallas D, Fernandez JB, Herman NG, Moursi A. Identification of pediatric Oral health Core competencies through Interprofessional education and practice. Nurs Res Pract. 2015;2015:360523.

8. Wong PD, Dave MG, Tulloch T, Feldman ML, Ford-Jones EL, Parkin PC, et al. Community health centres: potential opportunities for community paediatrics. From interprofessional clinical care to board governance. Paediatr Child Health. 2015;20(1):12-4

9. Stocker M, Pilgrim SB, Burmester M, Allen ML, Gijselaers WH. Interprofessional team management in pediatric critical care: some challenges and possible solutions. J Multidiscip Healthc. 2016;9:47-58.

10. Bode SF, Giesler M, Heinzmann A, Kruger M, Straub C. Self-perceived attitudes toward interprofessional collaboration and interprofessional education among different health care professionals in pediatrics. GMS J Med Educ. 2016;33(2):Doc17.

11. Reeves S. An overview of continuing interprofessional education. J Contin Educ Heal Prof. 2009;29(3):142-6.

12. Straub C, Krueger M, Bode SFN. Interprofessional education in pediatrics child protection and family services as a teaching example. Ann Anat. 2017; 213:62-8.

13. Wilhelmsson M, Pelling S, Ludvigsson J, Hammar M, Dahlgren LO, Faresjo T. Twenty years experiences of interprofessional education in Linkoping-ground-breaking and sustainable. J Interprof Care. 2009;23(2):121-33.

14. Pollard KC, Miers ME, Gilchrist M. Collaborative learning for collaborative working? Initial findings from a longitudinal study of health and social care students. Health Soc Care Community. 2004;12(4):346-58.

15. Pollard KC, Miers ME. From students to professionals: results of a longitudinal study of attitudes to pre-qualifying collaborative learning and working in health and social care in the United Kingdom. J Interprof Care. 2008:22(4):399-416.

16. Hood K, Cant R, Baulch J, Gilbee A, Leech M, Anderson A, et al. Prior experience of interprofessional learning enhances undergraduate nursing and healthcare students' professional identity and attitudes to teamwork. Nurse Educ Pract. 2014;14(2):117-22.

17. Bürgi H, Rindlisbacher B, Bader C, Bloch R, Bosmann F, Glasser C, et al. Swiss Catalogue of Learning Objectives for Undergraduate Medical Training2008 2015-07-17. Available from: http://sclo.smifk.ch/downloads/sclo_2008.pdf.

18. Frank JR. The CanMEDS 2005 physician competency framework. Betters standards. Better physisicans. Better care.2005 2015-07-17:[40 p.].

19. O'Halloran C, Hean S, Humphris D, Macleod-Clark J. Developing common learning: the new generation project undergraduate curriculum model. J Interprof Care. 2006;20(1):12-28.

20. IECEP IECEP. Core competencies for interprofessional collaborative practice: Report of an expert panel 2011.

21. Hahn EG, Fischer MR. National Competence-Based Learning Objectives for Undergraduate Medical Education (NKLM) in Germany: Cooperation of the Association for Medical Education (GMA) and the Association of Medical Faculties in Germany (MFT) GMS Z Med Ausbild. 2009;26(3):Doc35.

22. NKLM. National Competency-based Learning Objectives Catalogue in Medicine Kiel: GMA, MFT; 2015 [updated 2015/07/01.

23. Federal Ministry for Family Affairs SC, Women and Youth,. Training and examination regulations for the nursing professions. Berlin2018. p. 131.

24. Walkenhorst U, Mahler C, Aistleithner R, Hahn EG, Kaap-Frohlich S, Karstens $S$, et al. Position statement GMA Comittee - "Interprofessional Education for the Health Care Professions". GMS Z Med Ausbild. 2015;32(2):Doc22.

25. Herath C, Zhou Y, Gan Y, Nakandawire N, Gong Y, Lu Z. A comparative study of interprofessional education in global health care: a systematic review. Medicine (Baltimore). 2017;96(38):e7336.

26. Cichon I, Klapper B. Interprofessional approaches in undergraduate medical education. Bundesgesundheitsblatt Gesundheitsforschung Gesundheitsschutz. 2018;61 (2):195-200.

27. Murdoch NL, Epp S, Vinek J. Teaching and learning activities to educate nursing students for interprofessional collaboration: a scoping review. J Interprof Care. 2017:31(6):744-53.

28. Mueller D, Klingler R, Paterson M, Chapman C. Entry-level interprofessional education: perceptions of physical and occupational therapists currently practicing in Ontario. J Allied Health. 2008;37(4):189-95.

29. Parvizi N, Shahaney S, Martin G, Ahmad A, Moghul M. Republished: instigating change: trainee doctors' perspective. Postgrad Med J. 2013; 89(1056):572-7.

30. Wang Y, Liu YF, Li H, Li T. Attitudes toward physician-nurse collaboration in pediatric workers and undergraduate medical/nursing students. Behav Neurol. 2015;2015:846498.

31. Matziou V, Vlahioti E, Perdikaris P, Matziou T, Megapanou E, Petsios K. Physician and nursing perceptions concerning interprofessional communication and collaboration. J Interprof Care. 2014;28(6):526-33.

32. Mayring P. Qualitative content analysis. In: Fundamentals and Techniques [in German]. 12th ed. Weinheim: Beltz Pädagogik; 2010.

33. MacMillan KM. The challenge of achieving interprofessional collaboration: should we blame nightingale? I Interprof Care. 2012;26(5):410-5.

34. Cummings J, McArdle C, McQueen F, White J. UK chief nursing officers: shaping the future of the profession. Br J Nurs. 2017;26(9):498-500.

35. Koff SZ. Nursing in the European Union: anatomy of a profession: Taylor \& Francis Inc; 2016. 300 p.

36. Talwalkar JS, Fahs DB, Kayingo G, Wong R, Jeon S, Honan L. Readiness for interprofessional learning among healthcare professional students. Int J Med Educ. 2016;7:144-8.

37. Wilhelmsson M, Svensson A, Timpka T, Faresjo T. Nurses' views of interprofessional education and collaboration: a comparative study of recent graduates from three universities. J Interprof Care. 2013;27(2):155-60.

38. Zheng RM, Sim YF, Koh GC. Attitudes towards interprofessional collaboration among primary care physicians and nurses in Singapore. J Interprof Care. 2016;30(4):505-11.

39. Hood K, Cant R, Leech M, Baulch J, Gilbee A. Trying on the professional self: nursing students' perceptions of learning about roles, identity and teamwork in an interprofessional clinical placement. Appl Nurs Res. 2014; 27(2):109-14.

40. Roberts C, Kumar K. Student learning in interprofessional practice-based environments: what does theory say? BMC Med Educ. 2015;15:211. 
41. Berger S, Goetz K, Leowardi-Bauer C, Schultz JH, Szecsenyi J, Mahler C. Anchoring interprofessional education in undergraduate curricula: the Heidelberg story. J Interprof Care. 2017;31(2):175-9.

42. Fabry G, Fischer MR. Medical education in Germany--work in progress. GMS Z Med Ausbild. 2014;31(3):Doc36.

43. Straub C, Duerkop A, Bode SFN. Learning support on an interprofessional training ward. PADUA - Journal for nursing education, patient education and training. 2020

44. Mihaljevic AL, Schmidt J, Mitzkat A, Probst P, Kenngott T, Mink J, et al. Heidelberger Interprofessionelle Ausbildungsstation (HIPSTA): a practiceand theory-guided approach to development and implementation of Germany's first interprofessional training ward. GMS J Med Educ. 2018;35(3): Doc33.

45. Mette M, Baur C, Hinrichs J, Östreicher-Krebs E, E. N. Implementation of the Mannheim Interprofessional Training Ward (MIA: first evaluation results. GMS J Med Educ. 2019.

46. Mahler C, Berger SJ, Karstens S, Campbell S, Roos M, Szecsenyi J. Re-profiling today's health care curricula for tomorrow's workforce: establishing an interprofessional degree in Germany. J Interprof Care. 2015;29(4):386-8.

47. Mink J, Mitzkat A, Mihaljevic AL, Trierweiler-Hauke B, Gotsch B, Schmidt J, et al. The impact of an interprofessional training ward on the development of interprofessional competencies: study protocol of a longitudinal mixedmethods study. BMC Med Educ. 2019;19(1):48.

48. Peters S, Bode S, Straub C. Interprofessional training ward in paediatrics (IPAPAED) at the Centre for Paediatric and Youth Medicine Freiburg: overcoming borders - learning and working together. JuKiP. 2018;4(7):173-4.

49. Bode SFN, Giesler M, Heinzmann A, Krueger M, Straub C. Self-perceived attitudes towards interprofessional collaboration and education of different health care professionals in pediatrics. GMS Z Med Ausbild. 2016; under review.

50. Iller C, Wick A. Examinations as evaluation of competence acquisition in university education. Das Hochschulwesen. 2009;57(6):195-201.

51. Reis O, Ruschin S. Competence-oriented examination as central element of functioning modularisation in higher education. J Hochschuldidaktik. 2007; 18(2):6-9.

52. Schaper N, Reis O, Wildt J, Horvath E, BEnder E. Expert report on competence orientation in studies and teaching; 2012.

\section{Publisher's Note}

Springer Nature remains neutral with regard to jurisdictional claims in published maps and institutional affiliations.

Ready to submit your research? Choose BMC and benefit from:

- fast, convenient online submission

- thorough peer review by experienced researchers in your field

- rapid publication on acceptance

- support for research data, including large and complex data types

- gold Open Access which fosters wider collaboration and increased citations

- maximum visibility for your research: over $100 \mathrm{M}$ website views per year

At $\mathrm{BMC}$, research is always in progress.

Learn more biomedcentral.com/submissions 